\title{
ChemComm
}

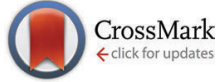

Cite this: Chem. Commun., 2014, 50, 11705

Received 27th June 2014

Accepted 1st August 2014

DOI: $10.1039 / c 4 c c 04910 a$

www.rsc.org/chemcomm

\section{Isomerisation of 1,4-dichlorobenzene using highly acidic alkali chloroaluminate melts $\nmid$}

\author{
J. Messner, ${ }^{a}$ P. S. Schulz, ${ }^{a}$ N. Taccardi, ${ }^{a}$ Sven Kuhlmann ${ }^{b}$ and P. Wasserscheid ${ }^{* a}$
}

\begin{abstract}
The isomerisation reaction of 1,4-dichlorobenzene leading to the thermodynamically favoured and technically desired 1,3-dichlorobenzene has been studied comparing highly acidic chloroaluminate melts with organic imidazolium and alkali metal ions. Interestingly, the inorganic melts show much higher reactivity and full recyclability if small $\mathrm{AlCl}_{3}$ losses are compensated and the reaction is carried out under slight $\mathrm{HCl}$ pressure.
\end{abstract}

Traditionally, Lewis acid catalysed reactions suffer from the need of hydrolysis for product isolation, causing the complete loss of the applied catalyst (e.g. $\mathrm{AlCl}_{3}$ ). Hence, liquid-liquid biphasic reaction systems with acidic ionic liquids are of great interest for more sustainable acid catalysis. Over the recent years, it has been demonstrated in a large number of publications ${ }^{1}$ that acidic ionic liquids allow a straightforward catalyst recycling by liquid phase separation, if none of the reactants form stable complexes with the acidic anions of the melt. Friedel-Crafts alkylations of aromatic compounds ${ }^{2,3}$ or alkane isomerisation reactions ${ }^{4}$ are among the prominent examples of this very successful strategy. Moreover, the physico-chemical properties of chloroaluminate ionic liquids, such as their melting points, ${ }^{5}$ viscosities ${ }^{6}$ and acidities, $^{7}$ are well understood. In contrast, acid catalysis with acidic alkali chloroaluminate melts is much less developed. This is mainly due to the marked difference in physical properties, such as melting points. While imidazolium chloroaluminates, such as 1-ethyl-3-methylimidazolium chloride ([EMIM]Cl)- $\mathrm{AlCl}_{3}$, form liquid systems over a wide range of composition at room temperature, ${ }^{6}$ the respective $\mathrm{LiCl}-\mathrm{AlCl}_{3}$ displays a melting point of $170{ }^{\circ} \mathrm{C}$ for $\chi\left(\mathrm{AlCl}_{3}\right)=0.67 .^{8}$ Despite these differences, anion speciation in both organic and inorganic chloroaluminates leads

\footnotetext{
${ }^{a}$ Lehrstuhl für Chemische Reaktionstechnik der Universität Erlangen-Nürnberg (FAU), Egerlandstrasse 3, D-91058 Erlangen, Germany.

E-mail: peter.wasserscheid@fau.de; Fax: +49 913185 27421;

Tel: +49 91318527420

${ }^{b}$ LANXESS Chemical (China) Co. Ltd., 5 Corporate Avenue, No. 150 Hubin Road, HuangPu District, Shanghai, 200021, P. R. China

$\dagger$ Electronic supplementary information (ESI) available: Experimental procedures, ICP, GC, and GC-MS data. See DOI: 10.1039/c4cc04910a
}

to quite a similar picture. Raman spectroscopy, ${ }^{9,10}$ mass spectroscopy (MS) ${ }^{11}$ and ${ }^{27} \mathrm{Al} \mathrm{NMR} \mathrm{spectroscopy}{ }^{12}$ have been applied to identify $\mathrm{Cl}^{-},\left[\mathrm{AlCl}_{4}\right]^{-},\left[\mathrm{Al}_{2} \mathrm{Cl}_{7}\right]^{-}$and $\left[\mathrm{Al}_{3} \mathrm{Cl}_{10}\right]^{-}$in organic and inorganic chloroaluminate melts. For systems with a molar fraction $\chi\left(\mathrm{AlCl}_{3}\right)<0.5$ only $\mathrm{Cl}^{-}$and $\left[\mathrm{AlCl}_{4}\right]^{-}$were found. Whereas $\left[\mathrm{Al}_{2} \mathrm{Cl}_{7}\right]^{-}$and $\left[\mathrm{Al}_{3} \mathrm{Cl}_{10}\right]^{-}$are the dominating species in melts with $\chi\left(\mathrm{AlCl}_{3}\right)>0.5{ }^{13,14}$ However, in contrast to organic chloroaluminates (where only $\left[\mathrm{AlCl}_{4}\right]^{-}$is found for $\chi\left(\mathrm{AlCl}_{3}\right)=$ $0.50),{ }^{14}$ inorganic chloroaluminate melts have been shown to contain acidic $\left[\mathrm{Al}_{2} \mathrm{Cl}_{7}\right]^{-}$species in equimolar chloride salt- $\mathrm{AlCl}_{3}$ mixtures. ${ }^{15}$ Simulation studies by Salanne et al. ${ }^{16}$ have confirmed this finding and claimed an increasing content of $\left[\mathrm{Al}_{2} \mathrm{Cl}_{7}\right]^{-}$in inorganic chloroaluminate melts of equimolar composition by going from the potassium over the sodium to the lithium system. IR measurements resulted in additional evidence for this important difference between organic and inorganic chloroaluminate melts. ${ }^{17}$ However, although spectroscopically confirmed, this property was so far poorly exploited for superior performance in technically relevant catalytic transformations. For both organic and inorganic chloroaluminate systems a further increase of the acidity is possible by adding hydrogen chloride gas ( $\mathrm{HCl})$. As such, addition leads to the formation of super acids, the individual acidity of the melt system is a direct function of the chloride salt/ $\mathrm{AlCl}_{3}$ ratio and the partial pressure of $\mathrm{HCl}$ gas. ${ }^{18,19}$

In this contribution we describe the use of acidic chloroaluminate melts, both with organic and inorganic cations, in the isomerisation reaction of 1,4-dichlorobenzene (1,4-DCB). The technical interest in this reaction originates from the fact that the chlorination of benzene with gaseous chlorine and using iron chloride as a catalyst leads typically to a kinetic product mixture of DCBs that contains much less 1,3-DCB than industrially needed. Due to the ortho-/para-directing effect of the primarily attached chloro substituent, the kinetic mixture contains mainly the 1,4- and 1,2-isomers and only small amounts of 1,3-DCB. However, 1,3-DCB is of high commercial interest as a feedstock for the synthesis of herbicides, insecticides, dyes and pharmaceuticals. Direct and selective synthesis routes to 1,3-DCB exist and are based on chlorination of 1,3-dinitrobenzene or on 
the Sandmeyer reaction of 3-chloroaniline. Both routes are much more expensive and much less atom efficient than direct benzene chlorination. Thus, the isomerisation of a kinetic DCB mixture to the 1,3-DCB-rich thermodynamic mixture is of significant technical interest. The thermodynamic equilibrium composition of DCB isomers at $150{ }^{\circ} \mathrm{C}$ is $60 \% 1,3-\mathrm{DCB}, 32 \% 1,4$-DCB and $8 \% 1,2-\mathrm{DCB}$.

The isomerisation of $1,4-\mathrm{DCB}$ is not a new transformation. Olah et $a .^{20}$ investigated this reaction in the 1960s using water promoted aluminium chloride as a catalyst. The isomerisation with $\mathrm{AlCl}_{3}-$ water is highly selective to form only the three DCB isomers together with small amounts of polychlorinated biphenyls. However, in the homogeneous Olah protocol, the $\mathrm{AlCl}_{3}$ catalyst has to be hydrolysed for product isolation, leading to complete loss of the catalyst.

In this contribution we report on alternative liquid-liquid biphasic reaction systems for the isomerisation of DCB that allows easy product isolation and complete recycling of the highly acidic catalyst phase. For this purpose, we applied organic and inorganic, acidic chloroaluminate melts. In detail, we investigated the isomerisation of 1,4-DCB comparing $\mathrm{AlCl}_{3}$-[EMIM] Cl and $\mathrm{AlCl}_{3}-\mathrm{MCl}$ $(\mathrm{MCl}=\mathrm{LiCl}$ or $\mathrm{LiCl}-\mathrm{NaCl})$ as reaction phases. As the DCB isomerisation requires strongly acidic conditions, all applied melts contained a molar ratio of $\chi\left(\mathrm{AlCl}_{3}\right)=0.67$. This was the maximal molar fraction of $\mathrm{AlCl}_{3}$ that allowed a reliable performance comparison between the different systems. In fact, the melting points of the $\mathrm{AlCl}_{3}-\mathrm{LiCl}$ system ${ }^{8}$ and the imidazolium system $^{6}$ increase drastically above this composition.

In order to achieve comparable starting points for the reaction, all melts were prepared and heated to $170{ }^{\circ} \mathrm{C}$ prior to adding the 1,4-DCB substrate. In case of the reference system, 1,4-DCB was placed in a preheated flask at $170{ }^{\circ} \mathrm{C}$ and a mixture of $\mathrm{AlCl}_{3}$ and $\mathrm{AlCl}_{3} \cdot 6 \mathrm{H}_{2} \mathrm{O}$ as a water donor was added directly to the organic component (for details of the experimental procedures see the ESI $\dagger$ ). For the experiments shown in Fig. 1, samples were taken every hour, dissolved in dichloromethane, extracted with water and analysed by GC.

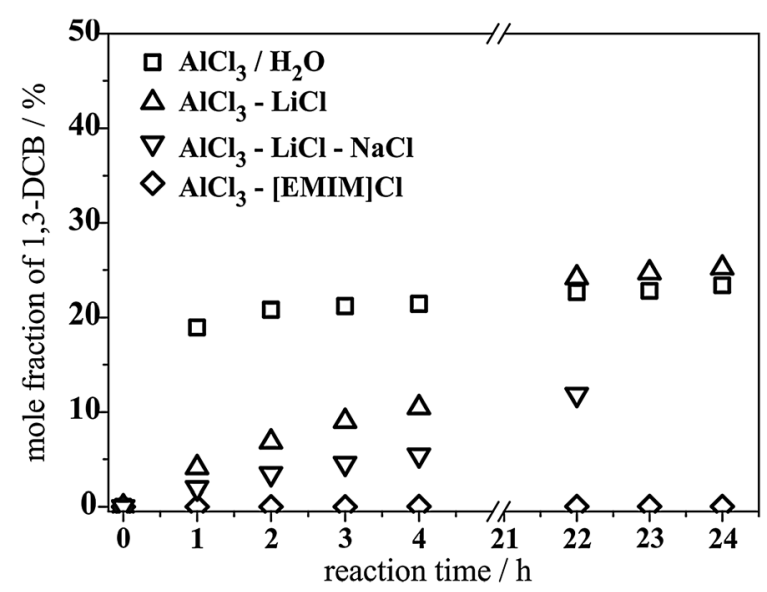

Fig. 1 Isomerisation of 1,4-dichlorobenzene with four different catalytic systems: ( $\square$ ) the reference system $20 \mathrm{~mol}_{\%} \mathrm{AlCl}_{3}$ and $10 \mathrm{~mol} \% \mathrm{H}_{2} \mathrm{O}$ in the form of $\mathrm{AlCl}_{3} \cdot 6 \mathrm{H}_{2} \mathrm{O} ;(\triangle) 20 \mathrm{~mol} \% \mathrm{AlCl}_{3}$ and $10 \mathrm{~mol} \% \mathrm{LiCl} ;(\nabla) 20 \mathrm{~mol} \%$ $\mathrm{AlCl}_{3}, 4 \mathrm{~mol} \% \mathrm{LiCl}$ and $6 \mathrm{~mol} \% \mathrm{NaCl} ;(\diamond) 20 \mathrm{~mol} \% \mathrm{AlCl}_{3}$ and $10 \mathrm{~mol} \%$ [EMIM]Cl, at $170{ }^{\circ} \mathrm{C}$.
Most interestingly, there is a drastic difference in reactivity between the inorganic chloroaluminate melts and the imidazolium system. While the latter hardly shows any isomerisation activity under the applied conditions, the inorganic melts show significant activity and after a reaction time of $22 \mathrm{~h}$ exceed the level of conversion that was realized with the homogeneous Olah system $^{20}$ (25\% vs. $23 \%$ conversion). Remarkably, the Olah system shows very high reactivity in the first hour $(19 \%$ conversion) while further reaction is very sluggish and only little extra conversion is observed in the following 23 hours. Comparing all chloroaluminate melts with the Olah reference system, it has to be kept in mind that all molten salt systems operate under liquid-liquid biphasic conditions while the $\mathrm{AlCl}_{3}$ is homogeneous in nature. In addition, it has to be stated that the Olah system was not easy to handle at a temperature of $170{ }^{\circ} \mathrm{C}$ due to $\mathrm{AlCl}_{3}$ sublimation and huge amounts of $\mathrm{HCl}$ gas evolving from the system. These problems were effectively minimized in all molten salt systems. In further experiments, we addressed the optimisation of the reaction conditions for the 1,4-DCB isomerisation using $\mathrm{AlCl}_{3}-$ LiCl. In particular, we were interested in two aspects: (a) the influence of $\mathrm{HCl}$ on the isomerisation reaction (formed from traces of humidity in the $\mathrm{LiCl}$ ); (b) the question whether recycling of the acidic melt is possible (saving large amounts of $\mathrm{AlCl}_{3}$ and avoid waste production from the $\mathrm{AlCl}_{3}$ hydrolysis).

In order to reveal the influence of dissolved $\mathrm{HCl}$ in the acidic molten salt, we compared the 1,4-DCB isomerisation reaction in an open flask with an otherwise identical reaction ( $4 \mathrm{~h}$ reaction time, $170{ }^{\circ} \mathrm{C}$ ) in a glass autoclave (see the ESI $\dagger$ for experimental details) where all the formed $\mathrm{HCl}$ gas was kept in the system (Fig. 2).

Very clearly, the isomerisation of 1,4-DCB was observed to proceed much more effectively in the autoclave experiment, with 1,3-DCB yields exceeding 45\%. Crossing this conversion limit was found to be of practical relevance, as the DCB isomeric mixtures are liquids at room temperature with a molar fraction of the 1,3 -isomer above $45 \%$. Thus, after the reaction the liquid organic layer can be easily decanted from the now solid molten salt at room temperature.

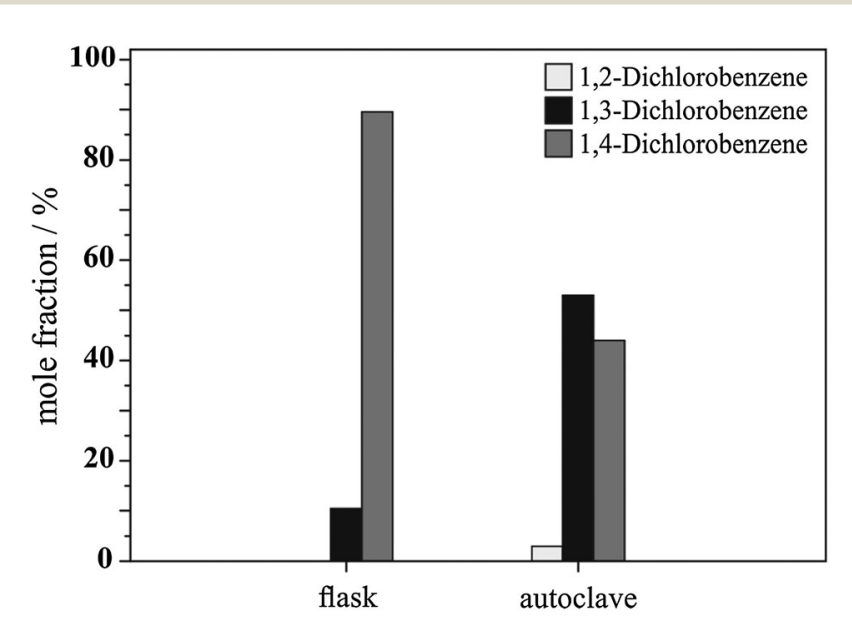

Fig. 2 Isomerisation of 1,4-DCB with $\mathrm{AlCl}_{3}-\mathrm{LiCl}$ in an open flask compared to the reaction in a closed autoclave; $170{ }^{\circ} \mathrm{C}, 4 \mathrm{~h}, 20 \mathrm{~mol} \% \mathrm{AlCl}_{3}$ and $10 \mathrm{~mol} \% \mathrm{LiCl}$. 


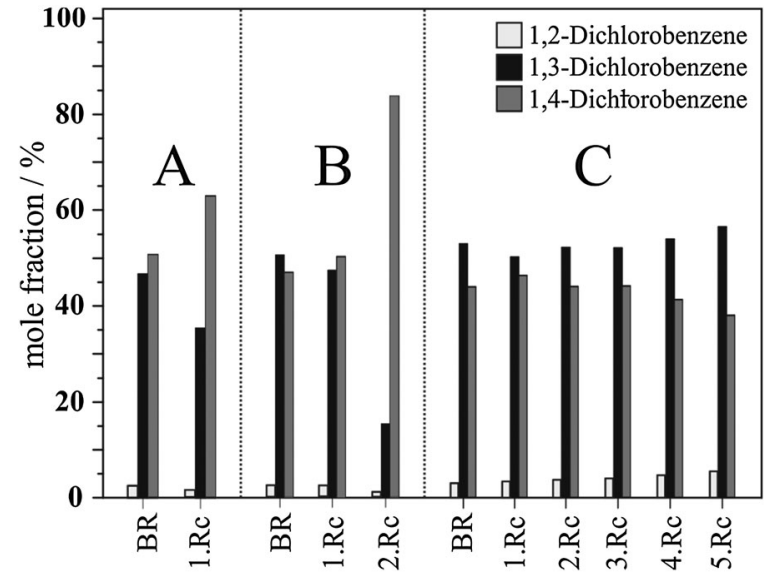

Fig. 3 Isomerisation of 1,4-DCB with $\mathrm{AlCl}_{3}-\mathrm{LiCl}(\mathrm{BR})\left(X_{\mathrm{AlCl}_{3}}=0.67\right)$ and melt recycling (RC) under various conditions: (A) substitution of leached $\mathrm{AlCl}_{3}$, no $\mathrm{HCl}$-gas added, (B) recycling with $\mathrm{HCl}$-gas added, no addition of $\mathrm{AlCl}_{3}$ (C) recycling with added $\mathrm{AlCl}_{3}$ and $\mathrm{HCl}$-gas $\left[170{ }^{\circ} \mathrm{C}, 4 \mathrm{~h}, 250 \mathrm{~g}\right.$ $(1.7 \mathrm{~mol})$ 1,4-DCB, $20 \mathrm{~mol} \%(45.4 \mathrm{~g}) \mathrm{AlCl}_{3}, 10 \mathrm{~mol} \%(7.21 \mathrm{~mol}) \mathrm{LiCl}$, recycling with $1 \mathrm{bar} \mathrm{HCl}$ and/or the addition of $\left.4.54 \mathrm{~g} \mathrm{AlCl}_{3}\right]$.

For recycling, the resulting solid molten salt was re-melted and fresh 1,4-DCB was added. Two special precautions proved to be necessary to allow recycling with a constant yield of 1,3-DCB.

First, the $\mathrm{AlCl}_{3}$ content of the organic product phase was analysed by ICP to determine the level of Al-leaching. This level was found to be about $3 \%$ of the previously applied $\mathrm{AlCl}_{3}$. Replacing this loss was found to be beneficial for the catalyst recycling. Secondly, it turned out that recycling is much more effective if after the product removal - a process that requires the opening of the reactor under inert gas -1 bar HCl-gas was added to the reaction system. Note that in an industrial scenario $\mathrm{HCl}$ is always omnipresent around an arene chlorination plant. With these two measures, the recycling of the acid catalyst phase worked indeed in an excellent manner with no loss of activity over at least five recycling runs (Fig. 3C). Thus, in comparison to the Olah system, ${ }^{21}$ the acidic lithium chloroaluminate system described here has three distinct advantages for DCB isomerisation: (a) drastic reduction of $\mathrm{AlCl}_{3}$ sublimation; (b) straightforward product isolation; and (c) re-use of more than $95 \mathrm{~mol} \%$ of the applied $\mathrm{AlCl}_{3}$ in subsequent isomerisation reactions.

In order to evaluate the scope of the new catalytic system for the isomerisation of other dihaloarene compounds, we also studied the isomerisation of 1-bromo-4-chlorobenzene (BCB) (see the ESI $\dagger$ for details). It was found that the reaction of the BCB substrate required less harsh reaction conditions compared to the fully chlorinated substrate as expected from literature reports. ${ }^{21}$

Interestingly, the acidic [EMIM $]^{+}$chloroaluminate melt exhibits reasonable catalytic activity towards the isomerisation of BCB still being much less reactive than its inorganic counterpart (Fig. 4). While the $\mathrm{AlCl}_{3}-\mathrm{LiCl}$ system reached $40 \%$ of the 1,3 isomer after less than 1 hour of reaction time, the same final yield took $22 \mathrm{~h}$ with the [EMIM] $]^{+}$melt of the same Al-content. A reasonable explanation for this marked difference in

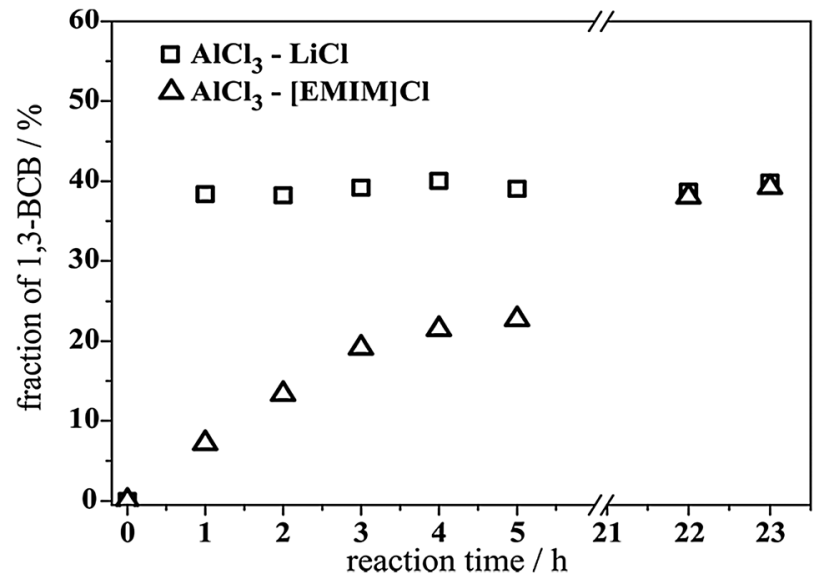

Fig. 4 Isomerisation reaction of 1,4-BCB with $\mathrm{AlCl}_{3}-\mathrm{LiCl}$ vs. $\mathrm{AlCl}_{3}-[\mathrm{EMIM]Cl}$ (both $X_{\mathrm{AlCl}_{3}}=0.67$ ); $170{ }^{\circ} \mathrm{C}, 4 \mathrm{~h}, 20 \mathrm{~mol} \% \mathrm{AlCl}_{3}$.

reactivity can be derived from the fact that the inorganic melt systems contain a higher concentration of acidic anions compared to the organic ones.

In conclusion we could demonstrate that alkali chloroaluminate melts - and in particular lithium chloroaluminate melts - form highly active and recyclable catalyst phases for the technically relevant reaction of dihaloarene isomerisation. ${ }^{22}$ Remarkable differences in reactivity have been found between inorganic chloroaluminate systems and their imidazolium analogues at the same molar ratio of $\mathrm{AlCl}_{3}$. It has been further demonstrated that $\mathrm{HCl}$ partial pressure plays an important role in the catalyst recycling, and thus obviously in the reactivity of the isomerisation system. Replenishing $\mathrm{AlCl}_{3}$ losses and applying 1 bar $\mathrm{HCl}$ during the reaction resulted in a fully recyclable catalyst system for at least five dichlorobenzene isomerisation cycles.

The authors thank LANXESS Deutschland GmbH for financial support and for permission to publish this research.

\section{Notes and references}

1 M. Earle, in Ionic Liquids in Synthesis, ed. T. Welton and P. Wasserscheid, Wiley-VCH, Weinheim, 2008.

2 S. J. Nara, J. R. Harjani and M. M. Salunkhe, J. Org. Chem., 2001, 66, $8616-8620$.

3 J. A. Boon, J. A. Levisky, J. L. Pflug and J. S. Wilkes, J. Org. Chem., 1986, 51, 480-483.

4 C. Meyer and P. Wasserscheid, Chem. Commun., 2010, 46, 7625-7627.

5 J. Estager, J. D. Holbrey and M. Swadzba-Kwasny, Chem. Soc. Rev., 2014, 43, 847-886.

6 A. A. Fannin, Jr., D. A. Floreani, L. A. King, J. S. Landers, B. J. Piersma, D. J. Stech, R. L. Vaughn, J. S. Wilkes and J. L. Williams, J. Phys. Chem., 1984, 88, 2614-2621.

7 J. Estager, A. A. Oliferenko, K. R. Seddon and M. Swadzba-Kwasny, Dalton Trans., 2010, 39, 11375-11382.

8 R. A. Carpio, A. A. Fannin, Jr., F. C. Kibler, Jr., L. A. King and H. A. Oye, J. Chem. Eng. Data, 1983, 28, 34-36.

9 R. J. Gale, B. Gilbert and R. A. Osteryoung, Inorg. Chem., 1978, 17, 2728-2729.

10 S. J. Cyvin, P. Klaboe, E. Rytter and H. A. Øye, J. Chem. Phys., 1970, 52, 2776-2778.

11 G. Franzen, B. P. Gilbert, G. Pelzer and E. DePauw, Org. Mass Spectrom., 1986, 21, 443-444. 
12 F. Taulelle and A. I. Popov, J. Solution Chem., 1986, 15, 463-471.

13 E. Rytter, H. A. Øye, S. J. Cyvin, B. N. Cyvin and P. Klaeboe, J. Inorg. Nucl. Chem., 1973, 35, 1185-1198.

14 H. A. Oye, M. Jagtoyen, T. Oksefjell and J. S. Wilkes, Mater. Sci. Forum, 1991, 73-75, 183-189.

15 R. S. Juvet, Jr., V. R. Shaw and M. A. Khan, J. Am. Chem. Soc., 1969, 91, 3788-3792.

16 M. Salanne, L. J. A. Siqueira, A. P. Seitsonen, P. A. Madden and B. Kirchner, Condens. Matter, 2013, 1-12.

17 J. Hvistendahl, P. Klaeboe, E. Rytter and H. A. Oeye, Inorg. Chem., 1984, 23, 706-715.
18 G. P. Smith, A. S. Dworkin, R. M. Pagni and S. P. Zingg, J. Am. Chem. Soc., 1989, 111, 5075-5077.

19 G. P. Smith, A. S. Dworkin, R. M. Pagni and S. P. Zingg, J. Am. Chem. Soc., 1989, 111, 525-530.

20 G. A. Olah, W. S. Tolgyesi and R. E. A. Dear, J. Org. Chem., 1962, 27, 3449-3455.

21 G. A. Olah, W. S. Tolgyesi and R. E. A. Dear, J. Org. Chem., 1962, 27, 3455-3464.

22 S. Kuhlmann, U. Böger, P. Wasserscheid, S. Schlenk, J. Messner and H.-M. Weber, WO 2013/189848, Lanxess Deutschland GmbH (Chem. Abstr., 2013, 993608). 